\title{
OCCULT INTUSSUSCEPTION
}

\author{
By G. T. WATTS, F.R.C.S. \\ Resident Surgical Officer, North Staffs Royal Infirmary
}

An acute intussusception is usually regarded as an emergency, and failure to recognise it an error. But from time to time there are reports of cases where a chronic intussusception has developed.

Most authors discussing the acute cases emphasise the history as much as the physical signs. In an analysis of a hundred cases made by Morrison and Court (1948); they found that of these pain, vomiting and blood were present in 39 per cent.; pain and vomiting alone in 34 per cent.; vomiting, blood and minimal pain in ro per cent.; vomiting only in 5 per cent.; pain and blood in 4 per cent.; pain in 4 per cent.; and blood alone in 4 per cent. Other authors have given only slightly different results. Few, however, admitted that difficulty in diagnosis was a frequent occurrence. It is strange, therefore, that an acute case is ever missed and allowed to become chronic or die. Snyder, Kraus and Chaffin (1949) whose results leave no doubt of their ability as surgeons, found difficulty in diagnosis in 15 per cent. of cases.

The true chronic intussusception was described classically by Still (192I), and other authors have added little to his description. Garvey and Kemp (1945) collected 62 cases and added $3 ;$ a few others have been added since then. The third case described below presented several of the characteristics of a chronic intussusception, although the lesion was only a week old at operation.

In the chronic case there is a sudden onset of abdominal pain, followed by irregularity of the bowels. There may be streaks of blood, but these are often dismissed as due to constipation. Following this phase, loss of appetite occurs, and the child loses weight; it is this which is usually the presenting symptom for the parents. By this time there is usually a tumour present. This resembles tuberculous omentum, the irregularity produced by the appendix and drawn-up mesentery on the right side resembling a mass of glands. Differentiation from a tuberculous lesion is difficult, even with the radiologist's help. We ourselves have seen one case of six months' duration. Pain had been slight and other symptoms few. A barium enema showed no abnormality whatsoever in the transverse colon at the site of the mass, and the diagonsis was finally made only by laparotomy.
The form of presentation varies, depending on the tightness of the intussusception. This also affects the speed at which symptoms appear. In case I the first symptom was vomiting for a week, often of a projectile nature (the child was sent to hospital as a case of congenital hypertrophic pyloric stenosis). Constipation for two days followed. Abdominal distension then became apparent, indicating subacute obstruction. A similar happening was reported by Forrester and Boyd (1950), although in their case, by the time the obstruction was recognized, the bowel was gangrenous. In case 2 , vomiting and erratic lower abdominal pain had been present for three days, and the child had become dehydrated. Constipation was again present for two days. In case 3 , irregular attacks of lower abdominal pain for three days had been accompanied by varying looseness of the stools. This was followed by complete constipation for one week, during which the child had no appetite. Distension, vomiting and pain, however, were absent. A similar case of chronic intussusception with loose stools was described by Medovy (I950). In all three of these cases a striking feature at operation was the ease with which reduction was effected, although oedema was always marked. In case $I$, in fact, there were signs that partial reduction has occurred spontaneously. A case in which this probably occurred was also described by Garvey and Kemp (1945).

\section{Case Reports}

Case I. Male, aged 9 months. The week before admission the child had vomited after all his feeds. The vomit had been projectile. The bowls had been normal until two days before admission. There were no obvious signs of colic. On examination, the child seemed to be ill, but no abnormality could be detected on clinical examination of the abdomen. The child was very reluctant to take feeds, but did not vomit after admission to hospital. By the following day there had been no bowel action, but a suppository produced a normal-looking stool. A test for occult blood was strongly positive. A few hours later slight abdominal distension appeared. At laparotomy an easily reduced ileocaecal intussusception was found. There was oedema, and 
there were also signs of bruising, showing that the intussusception had originally been more complete. Recovery was uneventful.

Case 2. Male, aged 2 years. For three days the child had suffered from irregular lower abdominal pain, which was never severe. The child had vomited several times in the previous two days, and there was complete anorexia. A normal stool had been passed during the first two days of the illness, but not on the day of admission. On examination, the child was ill and slightly dehydrated, and was almost constantly whimpering. Abdominal examination revealed no definite signs whatever, and there was normal faeces in the rectum. An occult blood test, however, was strongly positive. Laparotomy showed an easily reduced intussusception of the ileocaecal type. Recovery was uneventful.

Case 3. Female, aged 2 years. For three days the child had suffered from vague intermittent lower abdominal pain, and had vomited about a dozen times. The bowels had been opened on three occasions, the last, on the day of admission, being loose and brown. Examination showed an irritable, moderately ill child, but no other definite signs were present. The child was kept under observation for a week, and the pain disappeared fairly rapidly. There was, however, absolute constipation, which failed to respond fully to enemata on the 2nd and 7 th days, although no distension appeared. The stool obtained on the 7 th day was strongly positive for occult blood. At laparotomy an easily reduced ileocaecal intussusception was found. Oedema was very marked. Recovery was uneventful.

\section{Discussion}

Although it will be seen from the above cases that the precise manner of presentation is very variable, certain features do appear to be constant.

The first is that the child is always outwardly ill, and often suffering pain. The degree of anorexia and malaise are out of proportion to the clinical findings or the history. Anorexia is constantly present.

The next feature is the irregularity of bowel action. Usually there is constipation, but as in a case described by Medovy and in case 3 above, there can at times even be loose stools.

Thirdly, blood present in the stools may only be found by means of the occult blood test. This is unlike the normal case where blood is usually present as 'red-currant jelly.' Sometimes there is such quantity of blood that a diagnosis of dysentery may be made. Only a small amount of stool is necessary to test for occult blood-even the amount left on an examining finger. We have found this test positive in all three of the cases above, and it has also been so in our experience of $\frac{\varrho}{3}$ more obvious cases of intussusception where no $\stackrel{\mathbb{Q}}{\complement}$ macroscopic blood was passed. We therefore $c$. feel that, although the test is not diagnostic, it should be carried out in all cases where there is $\stackrel{5}{+}$ uncertainty about the cause of abdominal pain in $\bar{C}$ the child. If it is positive, further investigation must be carried out.

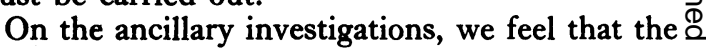
most useful is examination under anaesthesia. This was a great help in case 3 . Even when great $\overrightarrow{0}$ gentleness has allowed careful palpation in sleeping child, it is not always possible to be certain $\vec{\omega}$ that no tumour exists, and anaesthesia gives that added relaxation which is so useful.

A barium enema holds a doubtful position in the eyes of surgeons when treating intussusception. On the other hand, as many of these cases reduce $\omega_{\breve{~}}$ easily, it has the advantage of combining diagnosis $O$ and treatment.

Many surgeons suggest that in all cases of subacute or acute intussusception steps be taken to을 fix the bowel in some way that will prevent ${ }^{-}$ recurrence. Aird (1949) suggests sewing ileum $\mathbb{\Phi}$ and colon to each other. In view of the many $\Phi$ cases recorded where, despite such measures, 3 recurrence has occurred, this must be a matter for $\frac{\Phi}{-}$ individual decision at the time of operation. Fei $\vec{\varphi}$ surgeons, however, can resist dividing the naturato peritoneal folds when they appear to kink th ileocaecal angle! Appendicectomy probably has no real effect in preventing or promoting recurrence. We almost always remove the organ; it seems unreasonable to suggest that such a smallő extra measure is likely to have fatal consequences; the type of patient who will not stand so little $\overrightarrow{\vec{O}}$ more is the one on whom a greater load must 3 fall-resection of gangrenous bowel.

\section{Summary}

(I) Clinical features of occult intussusception have been compared with the acute and chronic 3 forms.

(2) The occult blood test has been of value in $\frac{0}{3}$ these cases for diagnosis.

(3) Examination undèr anaesthesia has been 을 valuable.

(4) A barium enema may be unreliable, but when used can effect reduction.

\section{BIBLIOGRAPHY}

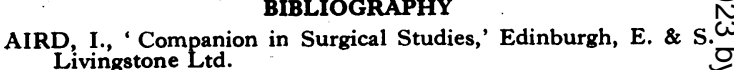

FORRESTER, M., and BOYD, J. (1950), Brit. med. F., 1i, 89. GARVIE and KEMP (1945), Arch. Dis. Child., 20, 73.

MEDOVY, H. (1950), Fournal-Lancet, 70, 188.

MORRISON, B., and COURT, D. (1948), Brit. med. F., 1, 776. SNYDER, W. H., KRAUS, A. R., and CHAFFIN, L. (1949), Ann. Surg., 130, 200.

STILL, G. F. (1921), Arch. Paed., 38, 174. 